\title{
Teaching Reform and Practice of Specialized Practice Courses
}

\author{
Xiangfeng $\mathrm{He}^{1, *}$ Yazhou Zhao ${ }^{1}$ Jing $\mathrm{Wu}^{1}$ Kefeng Fang $^{1}$ Hongwei Chen ${ }^{1}$ and Wei \\ $\mathrm{Ge}^{1}$
}

${ }^{1}$ College of Landscape Architecture, Beijing University of Agriculture, Beijing, 102206, China

* Corresponding author. Email: hxf791230@163.com

\begin{abstract}
It's important for the students majored in forestry and landscape architecture to cultivate the practical skills prior to their employment and future career. And College of Landscape Architecture, Beijing University of Agriculture offers practical courses, the Specialized Practice courses, for undergraduates. In this paper, the author probes into many issues existing in the teaching process, such as slow renewal of teaching content, repeated setting, lack of teaching base, and low initiative of students, and then come up with the appropriate solutions. By virtue of implementation of these measures, not only does it enhance the teaching effectiveness of this course, but also cultivate students' sense of teamwork and the ability to analyze and solve problems
\end{abstract}

Keywords: Specialized practice courses, Teaching reform, Teaching practice, College of landscape architecture.

\section{INTRODUCTION}

As for the colleges and universities, their main mission is to cultivate high-quality talents for the society. Currently, there exists a difficult issue that it is difficult for domestic undergraduates to find jobs, while employers can't recruit the talents needed. One of the important reasons is that colleges and universities attach more importance to theoretical teaching than practical teaching, which leads to undergraduates' incompetence for practical work [1]. To this end, the General Office of the State Council (2015) issued the Implementation Opinions concerning Deepening the Reform of Innovation and Entrepreneurship Teaching in Colleges and Universities in order to guide and solve the teaching dispatched with the practice in colleges and universities and shortage of practice platforms [2]. Beijing University of Agriculture attaches great importance to practical teaching, and sets the school running target of building a modern urban agricultural and forestry university and talent training target of the complex and application-oriented talents that have the innovative spirit and entrepreneurial ability in modern agricultural and forestry. The practical teaching team of College of Landscape Architecture sets two Specialized Practice courses I and II for undergraduates of forestry and landscape architecture specialties. Specialized Practice courses I include the collection and identification of flower seeds and bulb flowers, flower breeding, flower cultivation and management, fresh-cut flower preservation technology and other practical courses. Specialized Practice courses include seedling breeding skills such as soil preparation, seeding and breeding, cuttage breeding, grafting breeding and ramet breeding, as well as seedling maintenance skills such as seedling fertilization, irrigation and pruning. There are high requirements of practical operation for the students in the landscape architecture specialties and forestry specialties. The practical ability of the students will determine their employment and future career development [3]. Therefore, how to accomplish the teaching mission of practical courses with high quality has become an urgent problem to be solved by the practitioners of practical teaching in the higher agricultural and forestry colleges [4]. The teaching team has undertaken the Specialized Practice courses for a long time. Aiming at the main problems in the course of teaching, this paper puts forward some corresponding improving methods in combination with the teaching practice and experience of the curriculum group, so as to serve as references to improve the practical teaching 
quality of forestry and landscape architecture specialties in the future.

\section{PROBLEMS EXISTED DURING THE TEACHING PROCESS}

\subsection{The Teachers Themselves should Improve Their Practical Operation Ability}

Due to the limited teaching staff in Beijing University of Agriculture, the number of practical teachers is not enough. Although young teachers have been introduced into Beijing University of Agriculture in recent years, most of them who directly undertake the teaching work after graduation are younger and less experienced. As a result, they offer the practical teaching with low quality. Upon many years of curriculum construction, the number of practical teaching team has reached 6 staff, so that it can fulfill the teaching needs of 4 classes of undergraduates in landscape architecture specialties and forestry specialties. The teaching team is characteristic of the rejuvenation (the average age is less than 40 years old), high education background (all of them have doctoral degrees), and strong learning ability. However, most of the teachers undertake several courses of undergraduate and graduate at the same time, as well as many other tasks such as the guidance for postgraduates and undergraduate thesis. So there are few opportunities to study in the first production line, and it is difficult for them to organically combine theory with practice. Therefore, it is of great significance for young teachers to promote their theoretical and practical operation ability in close combination with the actual needs of social production, so as to improve the quality of practical teaching.

\subsection{Course Content Shares the Duplication with Other Practical Courses}

In the Syllabus 2016 implemented by Beijing University of Agriculture, Specialized Practice courses for landscape architecture specialties and forestry specialties are partially similar or overlapping with other practical courses. For instance, the cuttage breeding, grafting breeding and other practical skills practiced during the Nursery, Urban Forest Cultivation, Floriculture and other courses share the duplication with that of the Specialized Practice courses which are set up as the important practical operation skills for intensive training with different plant materials. As a result, students will feel that they have learned the relevant content, lacking feeling of freshness and initiative for the repeated teaching content of the course.

\subsection{It can't Meet the Needs of the Course in Terms of the Teaching Bases}

The construction and application of teaching base serve as the basis and guarantee of the practical courses for the smooth development. Restricted by the teaching site, the teaching quality is seriously affected in the early stage of the Specialized Practice courses. Due to the lack of special management personnel before 2018, it was not equipped with the special areas for different practical training contents in the teaching nursery garden, where it is filled with trees at the age of several years and even decades, and weeds grow. It is difficult to meet the teaching objectives specified in the Syllabus. Taking the cuttage learning as an example, it's not equipped with shade structures and other facilities in the teaching nursery garden. The course teachers could only coordinate with other teachers of the College, and combine scientific research and teaching organically to ensure the smooth development of teaching. However, influenced by various factors such as scientific research progress and experimental materials, it is usually difficult to complete the teaching mission in full accordance with the teaching schedule.

\subsection{Students Have the Low Initiative Towards the Teaching Courses}

Although Specialized Practice courses play an important role to cultivate students' practical ability, it is set up as an optional course that is limited by the total class hours of the training program in Beijing University of Agriculture. Compared with the elementary courses of Nursery, Floriculture, Dendrology and others in the specialty, students pay less attention to Specialized Practice courses, with low initiative and effect. And some students underestimate practical courses, resulting in low initiative towards Specialized Practice courses. While communicating with students, some students of forestry and landscape architecture specialties onesidedly hold that the skills taught in the practical courses are only needed by students who will be engaged in plant production in the future, which has little to do with their own future employment. As a result, these students have a negative response in the process of class, and it is difficult to achieve the expected teaching effect. Meanwhile, the practical training contents such as tree transplanting, soil preparation, pruning and so on in this course have great labor intensity, but the students have great differences in individual functioning. Consequently, it makes some students with poor physical strength feel afraid of difficulties, showing low participation. In addition, the teacher-centered models are dominated in most of the practical teaching, where the teaching content and the content of theoretic course are repeated. At the same time, students only operate in line with the process required by the practice training courses, because the specific task of each course is 
given. As a result, the practical course becomes a mere formality, which fails to achieve the goal of training students' practical operation ability.

\subsection{Teaching Content is not Updated in Time}

With the advancement of science and technology, more and more new technologies and new instruments are continuously applied in practical work. Subject to the funds and other factors, new technology and tools update slowly in the early teaching of Specialized Practice courses, which is now seriously out of step with the production. For instance, the electric pruning machine is used to prune landscape trees in the actual work, while only the ordinary pruning shears are adopted in teaching courses; In the actual production process of the companies such as nursery garden, the perforating machines of seedling transplantation and other mechanical equipment are used for seedling transplantation, but the shovels are adopted for operation in the teaching process. Therefore, it is difficult for students with the dated practical knowledge to cope with the actual work when they come to the relevant enterprise for internship.

\section{CORRESPONDING MEASURES OF TEACHING REFORM}

Taking the problems existing in the Specialized Practice teaching of the above majors into account, a series of teaching reform measures are carried out.

\subsection{Improve Teachers' Practical Skills by Various Means}

Aiming at the problem of teachers' lack of practical experience, the practical skills of the course teachers of Specialized Practice courses may be improved through various channels such as understanding the current situation of the industry development in the relevant enterprises, visiting and learning new technologies and new methods in enterprises, participating in the teaching training of practical courses and conducting internal discussions in the course groups. For example, the teachers of the curriculum group go to Huangfa Nursery in Beijing many times annually. Combined with production practice, they can learn new technologies and methods from the first production line. What's more, teaching seminars within the curriculum group are carried out at regular intervals, and veteran teachers with rich experience are invited to carry out teaching demonstrations to play the role of "spreading, helping and guiding" of excellent veteran teachers. Thus, it comprehensively improves the overall practical teaching level of teachers in the teaching curriculum group.

\subsection{Develop a New Syllabus and Rationalize the Course Content}

Taking the overlapping of Specialized Practice courses and the practical teaching content of other courses into account, the teachers of the concerned practical courses held a concentrative discussion while revising the new Syllabus in 2020 in order to avoid unnecessary repetition and overlapping in the subsequent teaching. In terms of the important and difficult practical contents such as grafting breeding, different plant materials will be selected in the course of practical courses, and new operation tools and methods will be introduced to enhance the initiative of students. Thus, the students can be fully improved in terms of the professional skills, team collaboration and other abilities as far as possible in the limited class hours.

\subsection{Strengthen the Construction of Teaching base and Purchase the Latest Practical Tools}

In order to improve the practical teaching quality of students comprehensively, the College of Landscape Architecture, Beijing University of Agriculture constructed a teaching nursery garden covering an area of nearly $10000 \mathrm{~m}^{2}$ with a lot of manpower and material resources in 2018, which mainly serves as the training sites for Specialized Practice courses. The planting areas, transplanting areas and tree pruning areas are set up in line with the course arrangement. At the same time, the shade shed and sand ponds are set up for practical teaching. It can fully meet the practical teaching missions of 4 classes in two specialties in the nursery garden annually. The teachers of this course group are responsible for the overall management in the teaching nursery garden, where it's equipped with special managers to ensure the normal use of teaching nursery. In addition, the teachers of this teaching team actively applied for the related teaching reform projects. With the aid of the teaching reform projects of the College of Landscape Architecture and Beijing University of Agriculture, they purchased the electric scissors, electric perforating machines and other practical equipment in order to ensure the close connection between the teaching contents and the actual production. The construction of the above hardware facilities has laid a solid foundation for the comprehensive improvement of the teaching quality of Specialized Practice courses.

\subsection{Make the Students Realize the Importance of this Course and Improve their Learning Initiative}

In view of the low initiative of students, we can illustrate the importance of the contents taught in Specialized Practice courses in the future work in order to enhance their attention and interest in learning. We can set an example of graduates working in the famous 
parks and enterprises such as the Summer Palace, the National Palace Museum, and the Huanglong Nursery. In their work, they used fertilization, irrigation, pruning, transplanting, and other practical operations that were taught in the practical courses. By setting the examples of their classmates, students will be able to realize that the knowledge taught in the course is so practically significant in their future work that their attitude toward learning will change from passive coping to active learning. Aiming at the problem that some students are afraid of difficulty due to the high labor intensity in the Specialized Practice courses, the electric equipment can be used to replace the original manual equipment, such as electric scissors and electric perforating machines. As a result, students can learn the application of new tools and reduce the physical consumption for the improvement of the teaching quality in an all-round way.

\subsection{Adopt Flexible Teaching Methods and Improve the Participation of the Students}

In order to cultivate the students' ability of integrating theory with practice during the teaching process, we can change the main content of practical training contents into preview, design experiment and prepare practice materials. Students arrange the experiment independently by group in class. In case of seedling contents, students can select suitable tree species according to their own interests or combined with the content of scientific research projects. Before seeding, students can consult the literature by themselves, deal with them in advance based on the characteristics of the selected tree species, plant them in practical classes and take charge of the follow-up management. The teaching method mentioned above improves the students' participation in the practical courses, which not only fosters students' ability to solve problems, but also cultivates students' ability to cooperate in a team. The teaching team collected such abundant text materials and video materials concerned training that the students can preview before class conveniently. What's more, these materials are uploaded to the teaching center platform of Beijing University of Agriculture for students to view and study at any time.

\section{CONCLUSIONS}

General Secretary Xi Jinping's proposal "Lucid waters and lush mountains are invaluable assets" fully reflects the importance our nation attaches to the construction of ecological civilization. Meanwhile, he also puts forward higher requirements for agricultural and forestry technical talents in our country. Therefore, how to cultivate students with extensive adaptability and certain expertise within a limited time is a huge challenge faced by every agricultural and forestry college ${ }^{[5]}$. Professional practical skills are a must for students specializing in forestry and landscape architecture. For the practitioners of practical teaching in the higher agricultural and forestry colleges, it has become an urgent problem to accomplish the teaching mission of practical courses with high quality [6]. Taking the Specialized Practice courses offered by College of Landscape Architecture, Beijing University of Agriculture as an example, this paper discusses the common issues in the practical course and comes up with appropriate solutions. By implementing these reform measures, it not only obviously enhances the teaching effectiveness of this course, but also offers great significance to train students' ability to analyze and solve problems.

\section{ACKNOWLEDGMENTS}

The author: He Xiangfeng, female, 1979, doctor, associate professor, forest tree genetics and breeding orientation. This work was supported by Forestry Professional Training Teaching Team Project (5046516646/041) and Construction fund of first class Landscape Architecture Specialty.

\section{REFERENCES}

[1] Zhang Mingzhong, Wang Hongli, Zhang Yongtao, Bi Jianjie, \& Qiang Wei Discussion and Practice on Construction of Practical Teaching Base of Forestry Specialties. Experimental science and technology, 2018, 16 (003), 175-177

[2] General Office of the State Council. Implementation Opinions concerning Deepening the Reform of Innovation and Entrepreneurship Education in Colleges and Universities. Chinese University Teaching, 2015, 000 (005), 4-6.

[3] Liu Yumin, Liu Yamin, Liu Yun, He Binghui, Yao Rongjiang, \& Zhang Yong, et al Reform Research on Practical Teaching of Forestry Specialties. Journal of Higher Education, 2020, 21: 132-134.

[4] 3 Xin and Wang Haixiang. (2020). Exploration and Research on Practical Teaching in Local Agricultural and Forestry Colleges and Universities under the background of "New Agricultural Science" Chinese Journal of Multimedia and Network Teaching (first ten-day issue) (03), 192193.

[5] Zang Rui and Wen Caiyi Teaching Reform and Practice of Ornamental Plant Pathology [J] University Education, 2018, 000 (012): 55-58.

[6] Qi Yujiao, Zhang Guangqi, Tan Wei, He Yuejun, \& Wei Xiaoli (2019). Discussion on the Reform of Comprehensive Practice Teaching Mode for Forestry Specialties of Guizhou University. Forestry Education in China, 037 (001), 19-23. 